\title{
MOTOR AND SENSORY FUSION IN MONKEYS: PSYCHOPHYSICAL MEASUREMENTS
}

\author{
R. S. HARWERTH ${ }^{1}$, E. L. SMITH, III ${ }^{1}$ and M. L. J. CRAWFORD ${ }^{2}$ \\ Houston, Texas
}

\begin{abstract}
SUMMARY
Motor and sensory fusion, the basic processes of binocularity, must be present for bifoveal fixation with true fusion and stereopsis during ordinary viewing. The characteristics of motor and sensory fusion have been established for patients with normal and subnormal binocular vision; the present report describes our psychophysical studies of these processes in the macaque monkey. Three recent investigations of motor and sensory fusion in monkeys are described. The studies involved: (1) the comparability of motor and sensory fusion in monkeys and humans with normal binocular vision, (2) the effects of an early period of abnormal binocular vision on motor and sensory fusion in monkeys, and (3) the contrast sensitivity for binocular disparity in monkeys with stereo-deficiencies. The results of these studies demonstrated an excellent homology between the normal binocular vision of monkeys and humans. We also found that a period of esotropia during infancy caused deficiencies in sensory fusion, but not motor fusion. In some monkeys, the sensory deficiency persisted over the entire range of binocular disparities that were compatible with stereopsis, while other subjects demonstrated normal stereo-sensitivity for the largest fusible binocular disparities. The stereo-deficiencies of these monkeys, along with other visual attributes, suggest that their binocular vision is a viable model for the binocularity of patients with subnormal binocular vision or the monofixation syndrome.
\end{abstract}

The macaque monkey is generally considered to be the best non-human model for investigations of both normal and clinically abnormal vision of humans. Although the quality of the monkey model has been based on a combination of anatomical and functional data, the validity of the model is best illustrated by

From: ${ }^{1}$ College of Optometry, University of Houston, Houston, Texas; and ${ }^{2}$ Department of Ophthalmology and Visual Science, University of Texas, Houston, Texas, USA.

Correspondence to: Ronald S. Harwerth, College of Optometry, University of Houston, Houston, TX 77204-6052, USA. Fax: +1(713) 743-2053. e-mail: rharwerth@uh.edu. psychophysical measures of the performance properties of their vision. Without exception, monocular visual functions in macaque monkeys have shown excellent qualitative agreement with data from humans. ${ }^{1-7}$ Binocular vision, in comparison, has been studied less extensively, with the previous studies primarily being demonstrations of stereopsis $^{8-12}$ and disparity vergence. ${ }^{13.14}$ More quantitative measures of the precision and accuracy of the normal binocular vision mechanisms in monkeys are necessary to assess the applicability of extrapolating data from experimentally induced, abnormal binocular vision in monkeys to clinical vision disorders in humans.

Because of their frontally located eyes and conjugate eye movements, it is obvious that monkeys have binocular vision, but there are reasons to wonder whether the performance properties of their binocular vision are the same as those of humans. The most important of these reasons is that the response properties of binocular vision are directly dependent upon the lateral separation of the eyes and the interocular separation of the macaque monkey's eyes is approximately one-half that of a human's. Consequently, the monkey's binocular convergence for any near distance (the ratio of the interocular separation and viewing distance) will be about one-half that of humans. In addition, binocular disparity, which is the specific stimulus for both changes in convergence and stereoscopic vision, is proportional to the difference between the convergence angles of objects at different distances. Therefore, the monkey's binocular disparities for objects in different depth planes will also be about one-half those for humans. These differences in the stimulus-response functions for ordinary binocular vision are substantial and might predict differences in the evolution of the oculomotor and/or perceptual components of binocular vision.

It is also important to examine both motor and 
sensory functions in monkeys because, although binocular disparity is a basic stimulus for both the components, they have fundamentally distinct response properties. Motor fusion is a closed-loop oculomotor reflex requiring relatively large retinal image disparities, while sensory fusion is an openloop perceptual phenomenon which responds to smaller disparities.

In addition to sharing binocular disparity as a primary stimulus, both motor and sensory fusion mechanisms go through sensitive periods of development during early life. ${ }^{15-26}$ When an infant's visual experience is normal throughout the sensitive period, then the motor and sensory fusion mechanisms ordinarily interact in a highly coordinated, interdependent manner to provide normal single binocular vision with stereoscopic depth perception. In contrast, if a condition such as strabismus interferes with normal development, the usual result is abnormal binocular vision and stereoblindness later in life. The developmental consequences of strabismus, however, may be mitigated by surgical intervention during the sensitive period for the development of binocular vision. ${ }^{27-35}$ Nevertheless, because sensory binocular vision is extremely vulnerable to abnormal early visual experience, the majority of children treated for strabismus develop a form of abnormal sensory binocular vision classified as subnormal binocular vision, ${ }^{32}$ microtropia, ${ }^{28.32}$ or the monofixation syndrome..$^{29,33}$ Interestingly, fusional vergence responses generally appear to be clinically normal in spite of the characteristic sensory deficits (foveal suppression and reduced stereoacuity).

The clinical characteristics of these forms of abnormal binocular vision are well documented, but relatively little is known about many of the fundamental response properties of binocular vision. The primary reason for this lack of information is the practical difficulty in conducting detailed investigations of sensory fusion in patients with anomalous binocular vision. The difficulties notwithstanding, because of the behavioural control and experimentation time inherent in animal psychophysics, these studies are more feasible in monkeys with experimentally induced anomalies of binocular vision.

The present report summarises a series of recent psychophysical investigations of oculomotor and sensory mechanisms of binocular vision in monkeys with normal and with abnormal binocular vision. The first investigation ${ }^{36}$ involved a comparison of binocular vision in monkeys and human subjects. These measurements were undertaken because, as mentioned earlier, the clinical applicability of studies of abnormal binocular vision in a monkey model will be conditional on the comparability of normal binocular vision in humans and monkeys. The second investigation $^{37}$ involved an assessment of motor and sensory fusion in experimental monkeys reared with a temporary esotropia during infancy. These monkeys demonstrated visual functions reminiscent of the vision of strabismic patients following surgical eye-alignment during infancy and, hence, may be considered an adequate model of the monofixation syndrome. The purpose of the third investigation ${ }^{38}$ was to evaluate the suprathreshold stereopsis of monkeys with deficient stereoacuities. In these studies, the contrast sensitivity of stereoscopic depth perception was determined over the range of binocular disparities between the lower and upper limits of stereopsis.

\section{MOTOR AND SENSORY FUSION IN NORMAL MONKEYS: THE COMPARABILITY OF BINOCULAR VISION IN HUMANS AND MONKEYS}

The clinical assessment of binocularity includes tests of both the oculomotor and sensory components of binocular vision that, traditionally, have been described as motor and sensory fusion. ${ }^{39,40}$ These components were also incorporated in Worth's original proposal for a scheme involving three hierarchical grades or degrees of fusion. ${ }^{39}$ In Worth's classification, first-degree fusion was defined as simultaneous perception, second-degree fusion was haplopia with a fusional amplitude, and the highest degree of fusion, third-degree fusion, was stereopsis. Exceptions to the concept of hierarchical degrees of fusion have been well noted ${ }^{41}$ but the concept aptly describes the necessary conditions and relevant tests for defining normal single binocular vision.

Thus, clinical tests of binocular vision are designed to determine a patient's ability to maintain bifoveal fixation (motor fusion) with haplopia and stereoscopic depth perception (sensory fusion). With these clinical procedures, the performance properties of motor and sensory fusion for humans with normal binocular vision have been well established. It would seem appropriate to utilise similar procedures to assess binocularity in macaque monkeys to determine how closely their binocular vision capabilities compare with those of humans. In the present study psychophysical measurements of nonius alignment (first-degree fusion), prism-induced disparity vergence (second-degree fusion or motor fusion) and relative depth discrimination for spatially localised stimuli (third-degree fusion) were compared in human and monkey subjects.

The subjects for these measurements were four humans with clinically normal binocular vision and four normally reared rhesus monkeys (Macaca mulatta). The monkeys were trained on two discrimination tasks, one requiring the discrimination of relative visual directions, for the studies of motor fusion, and the other requiring the discrimination of 
relative depth, for the studies of sensory fusion (see Harwerth et al. ${ }^{36}$ for details of the psychophysical methods).

The analysis of motor fusion responses utilised fixation disparity measurements derived from the animal's performance on a dichoptic nonius alignment task. The physical offset required to achieve subjective dichoptic alignment of the nonius targets provided a direct measure of the residual error of binocular eye alignment (the fixation disparity). ${ }^{42}$ Fixation disparities for a series of prismatic vergence stimuli were determined for both human and monkey subjects to determine the comparability of their motor fusion functions.

Examples of the fixation disparity-forced vergence functions for normal monkey and human subjects are presented in Fig. 1 (left and middle panels). These data demonstrate a strong inter-species similarity in disparity vergence (i.e. fusion reflex) over a substantial range of prism-induced retinal disparities. The magnitude of the fixation disparities increased systematically with increasing vergence stimulus values, especially for convergence stimuli, but the slopes of the functions are considerably shallower than the slope of the function for simple prismatic displacement. The forms of the disparity vergence, stimulus-response functions were somewhat variable across observers, as has also been shown for clinical patients, ${ }^{42-44}$ but for a given observer they were found to be consistent across all binocular fusion stimuli. In fact, the functions were also similar whether or not the fusion stimulus was present. The systematic stimulus-response relationship with only peripheral stimuli indicates that, for subjects with normal binocular vision, binocular mechanisms from peripheral vision are remarkably effective in eliciting a fusion reflex and, consequently, it is sensible that more centrally located contours would not have produced large effects on disparity vergence responses.

For the analysis of sensory fusion using measures of stereothresholds, the monkeys performed a discrimination of relative depth for spatially filtered stimuli. Their stereothresholds were determined by the binocular disparity required to obtain a $75 \%$ correct discrimination between crossed versus uncrossed disparities. To assess the comparability of sensory fusion in human and monkey subjects, stereothresholds as a function of the spatial frequency of the stimulus were measured for both species.

The stereothresholds for four control monkeys are presented in Fig. 2 (left panel) for a range of nominal spatial frequencies of 0.25 to 16 cycles per degree (c/ $\mathrm{deg}$ ) for the difference-of-Gaussian (DoG) stimuli. ${ }^{45,46}$ In agreement with previous investigations in humans, ${ }^{46,47}$ the stereothreshold versus spatial frequency functions for monkeys can be well described by two linear segments: one segment, for spatial frequencies below 2-4 c/deg, with a negative slope close to $1.0(-1.06$ to -0.86 for the four monkeys), and another segment, for higher spatial frequencies, with a slope near zero. The negativesloped portion of the function is consistent with a threshold disparity determined by a constant phase shift of approximately $4 \mathrm{deg}$ (3.09-5.43 deg for the four monkeys) between the DoG stimuli in the two stereo half-views, while the zero-sloped portion indicates a disparity threshold that was determined by a constant positional offset between the stereoscopic stimuli of approximately 20 arcsec (16-24 arcsec for the four monkeys).

The stereothreshold functions for control monkeys are virtually identical to those of humans with normal binocular vision. A comparison of data from the two species is presented in Fig. 2 (middle panel). The stereothresholds for four human subjects
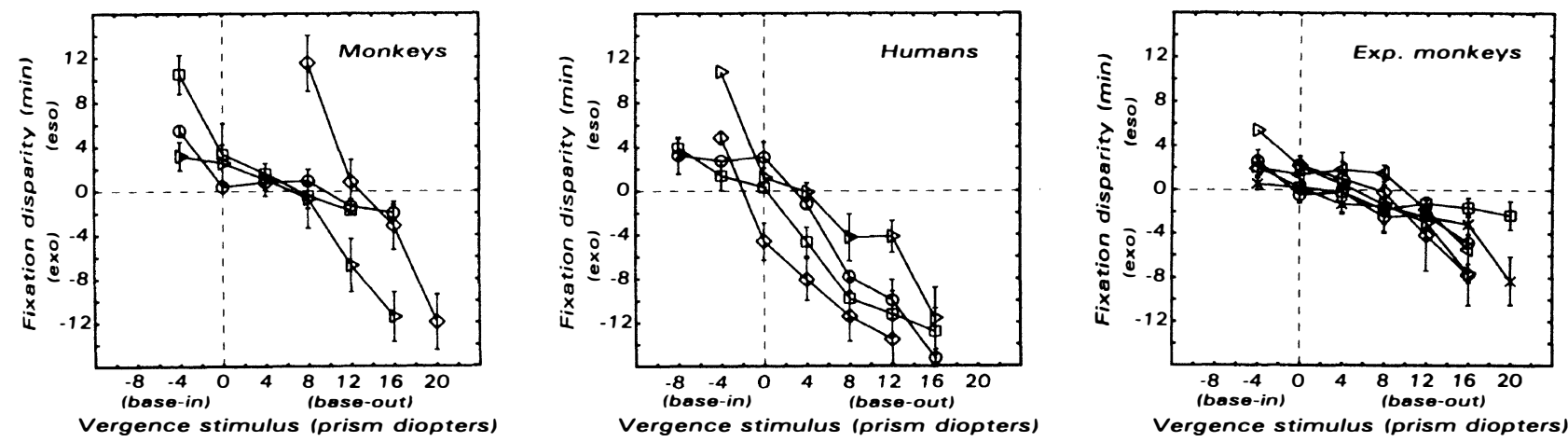

Fig. 1. Fixation disparity (vergence error) as a function of prism-induced disparity vergence. Eso-fixation disparities (overconvergence) are plotted as positive values and exo-fixation disparities (under-convergence) are plotted as negative values. Base-in prism (divergence) stimuli are designated as negative values and base-out (convergence) stimuli are designated as positive values on the abscissa. The binocular fusion stimulus was a 2 c/deg sine-wave grating. Left: Data for four control monkeys. Middle: Data for four human subjects with normal binocular vision. Right: Data for six monkeys with a period of early abnormal visual experience via surgically induced esotropia. 

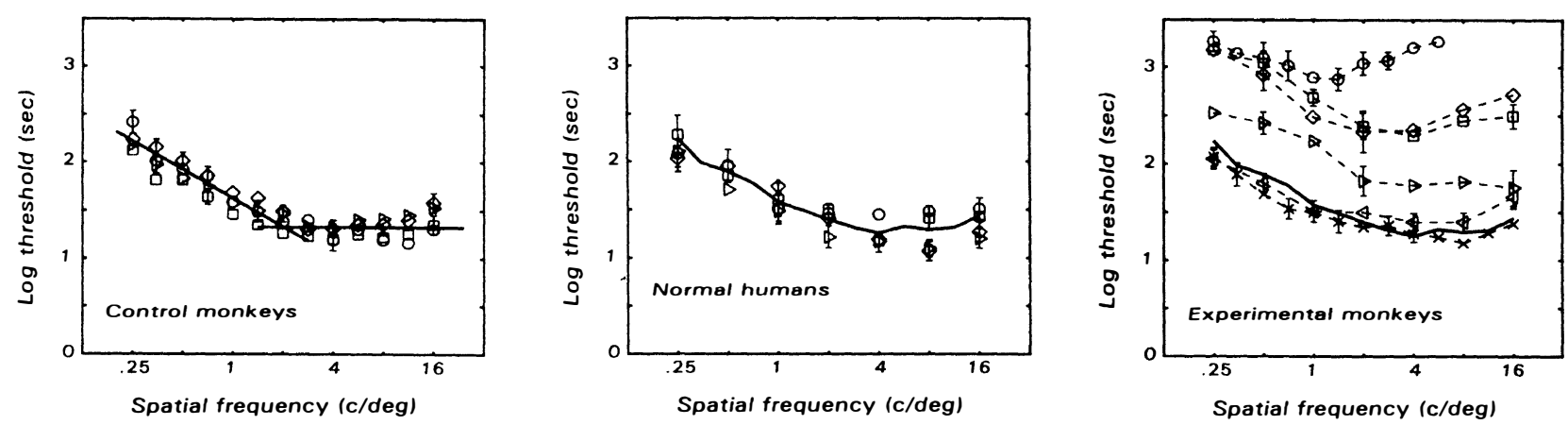

Fig. 2. Binocular disparity thresholds as a function of the spatial frequency of difference-of-Gaussian (DoG) stimuli. Left: Stereothreshold data for four control monkeys. The mean threshold data were fitted by two line segments, one segment with a slope of -1 for data from DoG spatial frequencies of 0.25-2.0 c/deg and another segment with zero slope for data from DoG spatial frequencies of 4.0-16 c/deg. Middle: Stereothreshold data for four human subjects with normal binocular vision. The bold line represents the mean thresholds for control monkeys (data from left panel). Right: Stereothreshold data from six experimental monkeys reared with a period of experimentally induced esotropia. For comparison, the bold line represents the mean thresholds from control monkeys.

are represented by the open symbols and the average thresholds for the four monkeys are represented by the heavy line. The agreement between the functions is remarkable and clearly demonstrates the similarities in the angular threshold disparities for local stereopsis in monkeys and humans.

Taken together, this series of measurements has shown comparable behaviour in rhesus monkeys and humans for each of Worth's three degrees of fusion. After compensation for the differences in the lateral separation of their eyes, the operating characteristics of disparity vergence and stereoscopic vision of the two species are indistinguishable and, consequently, the performance limits for these visual functions must be determined by anatomical and/or neural constraints that are similar in both species. Further, if the normal mechanisms of binocular vision are the same, then it may be assumed that abnormal visual development should cause similar binocular vision anomalies, which substantiates the clinical relevance of studies of abnormal binocular vision in monkeys.

\section{STEREO-DEFICIENCIES IN MONKEYS WITH TEMPORARY STRABISMUS: A MODEL FOR THE MONOFIXATION SYNDROME}

Of the attributes comprising the post-surgical vision of strabismic patients, perhaps the most interesting aspect concerns the differences in their second and third degrees of fusion; generally they have deficient stereopsis or stereoblindness while their fusional vergence amplitudes are normal. ${ }^{29,32}$ Consequently, it appears that early abnormal visual experience may have different effects on the motor and sensory components of binocular vision. However, except for clinical characterisations of binocularity following surgical interocular alignment, ${ }^{27-35,48-50}$ very little is known about the functional binocular vision of these patients. In one study, although Schor and his colleagues $^{46,51}$ reported elevated stereothresholds with normal upper limits of stereoscopic vision in strabismic patients, they provided little clinical information about the patients. Other investigations have relied on single measurements of stereoacuity. $28,35,48-50$

The purpose of the present investigation was to quantify the spatial frequency response functions for disparity vergence and stereopsis in monkeys that demonstrated the major characteristics of the clinical entity known as subnormal binocular vision ${ }^{32,34}$ or the monofixation syndrome..$^{29,33}$ The six monkeys used in these experiments were originally treated to induce a constant, unilateral esotropia of 10-20 deg, but when they were old enough for behavioural testing, we found that they had regressed to orthotropia with unrestricted eye movements. Subsequent behavioural measures confirmed normal realignment of their eyes and normal disparity vergence functions. In addition, some of the monkeys were mild amblyopes and some had deficient stereopsis. Altogether, the visual attributes of these monkeys seemed typical of the post-surgical status of many strabismic patients and studies of their binocular vision should be pertinent to the clinical entities known as subnormal binocular vision ${ }^{32,34}$ or the monofixation syndrome. ${ }^{29,33}$

Examples of their fixation disparity versus forced vergence functions are presented in Fig. 1 (right panel). The data demonstrate that, although the monkeys had undergone extraocular muscle surgery and had experienced a period of esotropia during infancy, they subsequently recovered normal eye alignment and disparity vergence. It is important to note that the fusional vergence functions for the experimental animals with prior strabismus are indistinguishable from those of control animals or humans with normal binocular vision (cf. Fig. 1, right and left panels). Thus, it can be concluded that, within the limits of psychophysical assessments of 
oculomotor responses, these monkeys had recovered orthotropic eye alignment and had developed normal motor fusion amplitudes, i.e. first- and second-degree fusion, that should have been compatible with thirddegree fusion.

The experiments on stereo-depth discrimination clearly demonstrated that each of the monkeys had stereopsis, but the individual responses varied from being essentially normal to a severe stereo-deficiency. Stereothreshold functions for each of the six monkeys are shown in Fig. 2 (right panel). Four of the monkeys demonstrated substantial stereo-deficiencies with their final measurements revealing functions that paralleled the threshold function of normal stereopsis (continuous line). This finding may be important because the shape of the spatial frequency response function has been considered a reflection of the disparity channels underlying stereopsis. ${ }^{52,53}$ Therefore, it appears that the main differences in stereopsis across the experimental subjects, in comparison with control subjects, is in degree, rather than kind, i.e. all the monkeys had stereoscopic vision but some had highly elevated thresholds. Further, the degree of stereo-deficiency was not, in any obvious way, related to the age at which the surgical esotropia was induced or whether the period of strabismus caused an amblyopia.

These investigations of the sensory and motor components of vision in monkeys reared with abnormal binocular vision have illustrated an interesting quantitative component in Worth's degrees of fusion, i.e. normal second-degree fusion but abnormal third-degree fusion. It is, however, important to mention that the number of subjects was small and that only one aspect of stereopsis was investigated: local stereopsis with high-contrast stimuli. It remains to be determined whether other aspects of stereopsis, for instance, global stereopsis, ${ }^{54}$ are similarly affected. In either case, these studies have demonstrated an experimental animal with the major characteristics of the monofixation syndrome, i.e. a period of strabismus, mild amblyopia, normal fusional vergence ranges, and elevated stereothresholds, that should be an adequate model for psychophysical and physiological investigations of residual binocularity following the surgical treatment of infantile strabismus.

\section{SUPRATHRESHOLD STEREOPSIS IN MONKEYS WITH STEREO-DEFICIENCIES: CONTRAST SENSITIVITY FUNCTIONS FOR BINOCULAR DISPARITY}

The experiments described above have demonstrated elevated stereothresholds in a group of monkeys whose visual attributes were characteristic of subnormal binocular vision. However, in addition to the well-documented reduction in stereo- acuity, ${ }^{48-50}$ it is important to understand the stereovision of these patients for the suprathreshold binocular disparities which are typically encountered in normal visual environments. It would be expected that binocular disparities larger than threshold would contribute to a perception of stereoscopic depth which could either normalise at some suprathreshold disparities or remain abnormal across the entire range of disparities for single binocular vision. To investigate stereoscopic vision over a large range of binocular disparities, contrast sensitivity for depth discrimination was measured for disparities between the lower and upper limits of local stereopsis in normal controls and stereo-deficient monkeys.

Depth discrimination data were obtained by two different procedures for determining disparity and contrast thresholds: (1) for small disparities, disparity thresholds were measured as a function of contrast, and (2) for larger disparities, contrast thresholds were measured as a function of disparity. The data from the two types of measurements were combined to obtain functions of contrast sensitivity versus binocular disparity.

Examples of the contrast sensitivity versus disparity functions for a low spatial frequency stimulus $(0.5 \mathrm{c} / \mathrm{deg})$ are presented in Fig. 3 for two control monkeys (left panel) and two experimental animals (middle panel). The functions for the control animals are similar to published data for humans,${ }^{55-57}$ but the functions for the experimental monkeys illustrate interesting deviations. The data presented in Fig. 3 (middle panel) are from one animal with a relatively mild stereo-deficiency (circles), another monkey with a more severe stereo-deficiency (squares) and, for comparison purposes, the average sensitivity from the two control monkeys (bold lines). It can be seen that the contrast sensitivity function for the subject with the milder stereo-deficiency is steeper than normal over the lower disparities, reaching normal sensitivity at approximately $10 \mathrm{arcmin}$. The data for the other subject did not reach a normal sensitivity at any disparity; the entire function is shifted towards higher disparities and lower contrast sensitivities. It is important to mention that the reduced contrast sensitivities for stereoscopic stimuli in these subjects cannot be explained simply by reduced sensitivities (amblyopia) for the DoG stimuli because the contrast sensitivities were similar for control and experimental monkeys.

To strengthen the clinical relevance of these animal studies, contrast sensitivity for binocular disparity functions was also measured on a human with normal binocular vision and a human stereoamblyope. The contrast sensitivity functions for the normal human and monkey subjects are indistinguishable (Fig. 3, right panel; circles for the human data, bold lines for the mean of the two control 

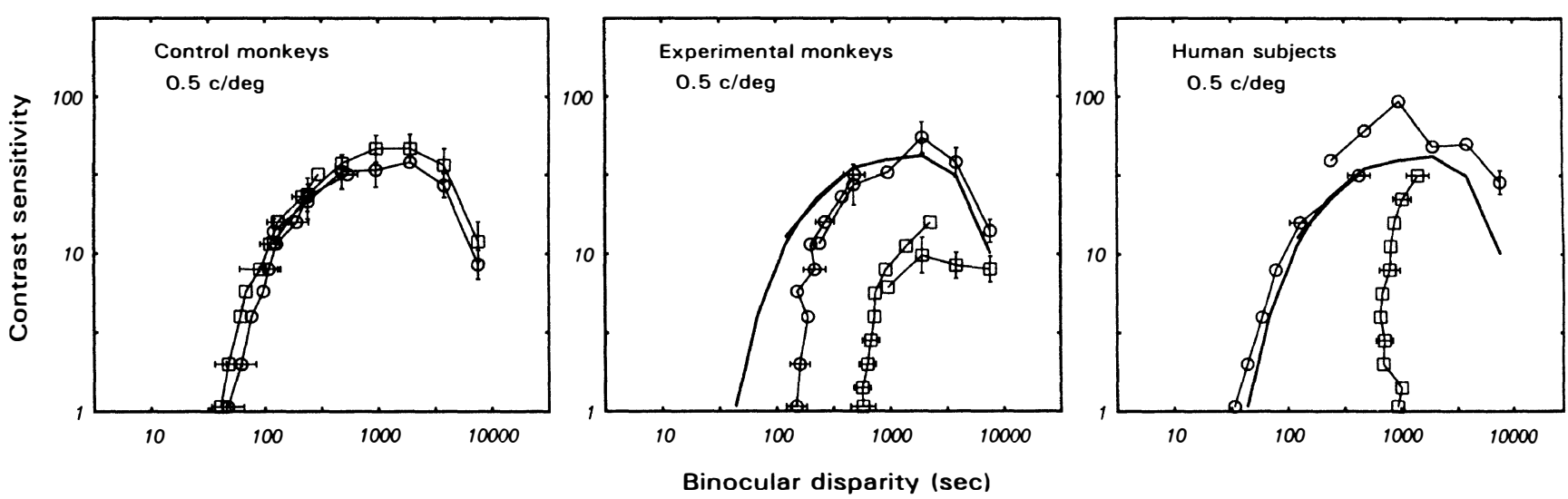

Fig. 3. Contrast sensitivity for binocular disparity with DoG stimuli of $0.5 \mathrm{c} /$ deg. Left: Contrast sensitivity functions for two control monkeys. Middle: Contrast sensitivity functions for two monkeys (circles and squares) reared with a period of experimentally induced esotropia. The bold line represents the mean sensitivities for the two control monkeys (left panel). Right: Contrast sensitivity functions for two human subjects, one with normal binocular vision (circles) and an idiopathic stereo-amblyope (squares). The bold line represents the mean sensitivities for the two control monkeys (left panel).

monkeys), providing additional evidence for identical processes for normal stereopsis in the two species. Similarly, the main features of the stereo-amblyope's function (Fig. 3, right panel; squares) were similar to those for one of the stereo-deficient monkeys (Fig. 3, middle panel), except that the position of the entire curve was displaced towards higher binocular disparities for the human subject.

The results of these measurements of contrast sensitivity functions for subjects with threshold stereo-deficiencies for high-contrast stimuli have illustrated two types of responses for stimuli of lower contrasts. The uniform reduction of contrast sensitivity for binocular disparities, illustrated by the monkey with the more severe stereo-deficiency (Fig. 3 , middle panel; squares), can be explained by a reduction in the number of cortical disparity processing mechanisms, without necessarily a quantitative change in the response properties of the residual mechanisms. ${ }^{58}$ The unusually steep contrast response functions found for the other monkey (Fig. 3, middle panel; circles) and the human stereo-amblyope (Fig. 3 , left panel; squares) indicate that the residual disparity processing mechanisms have high contrast thresholds, but low contrast gains. Thus, the data from these experiments predict that there should be a range of suprathreshold stereo-perception for patients with subnormal binocular vision. In some cases, normal stereodepth should occur for suprathreshold stimuli, but for other cases normal stereoscopic vision would not be present at any disparity magnitude.

\section{CONCLUSION}

Our studies of binocularity in normal monkeys have shown that monkeys, as well as humans, have motor fusion reflexes that compensate for a broad range of vergence demands and allow the reliable extraction of stereoscopic depth information. The sensitivities of the oculomotor and perceptual processes to binocular disparities are quite similar in the two species, but in a natural environment, because of the difference in their interocular separation, the differences in distances needed to exceed the disparity thresholds for fusional vergence or stereopsis must be twice as large for the monkey as for the human. On the other hand, the similarity in their sensitivities to binocular disparities indicates that the neural mechanisms underlying binocular vision are essentially identical in humans and monkeys. Hence, these data provide a rationale for a direct extrapolation of data from laboratory studies of abnormal binocular vision in monkeys to clinical vision disorders.

Our investigations of abnormal early visual experience demonstrate that a temporary experimental esotropia during infancy can cause specific sensory binocular vision anomalies that were not explained by oculomotor or monocular spatial vision deficits. It is important to note, however, that even the monkeys with high stereothresholds demonstrated stereopsis for the coarse binocular disparities required to initiate and sustain disparity vergence eye movements. As a result, in agreement with Schor's studies ${ }^{46,51}$ we found that the differences in stereopsis between subjects with normal stereopsis and those with stereo-deficiencies were quantitative threshold differences rather than missing classes of disparityprocessing mechanisms. ${ }^{59}$

The investigations of contrast sensitivity as a function of binocular disparity showed that each of the monkeys was capable of stereoscopic depth discrimination over a range of binocular disparities. For some of the monkeys, the disparity range was restricted at the low disparity end (the lower disparity limits), but the largest disparities compatible with stereoscopic depth perception (the 
upper disparity limits) were the same for both the control and experimental animals. In some cases, the contrast response properties of stereopsis appeared to be normal for suprathreshold disparities, while in other cases the threshold deficits persisted across all disparities.

In conclusion, it appears that a temporary strabismus in monkeys caused developmental vision deficits that were specific for the mechanisms of Worth's third-degree fusion, while not affecting the mechanisms for first- or second-degree fusion. At face value, these monkeys appear to be an excellent research model for patients with subnormal binocular vision or monofixation syndrome as a result of strabismus surgery during early childhood.

This work was supported by research grants EY 01139 and EY 03611 and core grant EY 07551 from the National Eye Institute, Bethesda, Maryland. We thank Dr G. K. von Noorden for performing strabismus surgery on the experimental monkeys.

Key words: Binocular vision, Disparity, Monkeys, Psychophysics, Stereopsis, Strabismus, Vergence.

\section{REFERENCES}

1. Blough DS, Schrier AM. Scotopic spectral sensitivity in the monkey. Science 1963;139:493-4.

2. DeValois RL, Morgan HC, Polson MC, Mead WR, Hull EM. Psychophysical studies of monkey color vision. I. Macaque luminosity and color vision tests. Vision Res 1974;14:53-67.

3. DeValois RL, Morgan HC, Snodderly DM. Psychophysical studies of monkey vision. III. Spatial luminance contrast sensitivity tests of macaque and human observers. Vision Res 1974;14:75-81.

4. Merigan WH. Temporal modulation sensitivity of macaque monkeys. Vision Res 1980;20:953-9.

5. Golamb B, Andersen RA, Nakayama K, MacLeod DIA, Wong A. Visual shearing motion in monkey and man. Vision Res 1985;25:813-20.

6. Harwerth RS, Smith EL. The rhesus monkey as a model for normal vision of humans. Am J Optom Physiol Optics 1985;62:633-41.

7. Harwerth RS, Smith EL, DeSantis L. Behavioral perimetry in monkeys. Invest Ophthalmol Vis Sci 1993;34:31-40.

8. Bough EW. Stereoscopic vision in the macaque monkey: a behavioral demonstration. Nature 1970;225:42-4.

9. Cowey A, Parkinson AM, Warnick L. Global stereopsis in rhesus monkeys. Q J Exp Psychol 1975;27:93-109.

10. Sarmiento RF. The stereoacuity of macaque monkeys. Vision Res 1975;15:493-8.

11. Harwerth RS, Boltz RL. Behavioral measures of stereopsis in monkeys using random dot stereograms. Physiol Behav 1979;22:229-34.

12. Harwerth RS, Boltz RL. Stereopsis in monkeys using random dot stereograms: the effect of viewing duration. Vision Res 1979;19:985-91.

13. Boltz RL, Harwerth RS. Fusional vergence ranges of the monkey: a behavioral study. Exp Brain Res 1979;37:87-91.

14. Boltz RL, Smith EL, Bennett MJ, Harwerth RS. Vertical fusional vergence ranges of the rhesus monkey. Vision Res 1980;20:83-5.
15. Hubel DH, Wiesel TN. The period of susceptibility to the physiological effects of unilateral eye closure in kittens. J Physiol (Lond) 1970;206:419-36.

16. Banks MS, Aslin RN, Letson RD. Sensitive period for the development of human binocular vision. Science 1975;190:675-77.

17. Vagen, Taylor D. Critical periods for deprivation in children. Trans Ophthalmol Soc UK 1979;99:432-9.

18. Wiesel TN. Postnatal development of the visual cortex and the influence of environment. Nature 1982; 299:583-91.

19. Boothe RG, Dobson V, Teller DY. Postnatal development of vision in human and nonhuman primates. Annu Rev Neurosci 1985;8:495-545.

20. Harwerth RS, Smith EL, Crawford MLJ, von Noorden GK. Behavioral studies of the sensitive periods of development of visual functions in monkeys. Behav Brain Res 1990;41:179-98.

25. Archer SM, Sondhi N, Helveston EM. Strabismus in infancy. Ophthalmology 1989;96:133-7.

26. Archer SM. Detection and treatment of congenital esotropia. In: Simons K, editor. Early visual development: normal and abnormal. Oxford: Oxford University Press, 1993:349-63.

27. Ing MR, Costenbader FD, Parks MM, Albert DG. Early surgery for congenital esotropia. Am J Ophthalmol 1966;61:1419-27.

28. Helveston EM, von Noorden GK. Microtropia, a newly defined entity. Arch Ophthalmol 1967;78:272-81.

29. Parks MM. Monofixation syndrome. Tran Am Ophthalmol Soc 1969;67:609-57.

30. Taylor DM. Is congenital esotropia functionally curable? Trans Am Ophthalmol Soc 1972;70:529-76.

31. Ing MR. Early surgical alignment for congenital esotropia. Ophthalmology 1983;90:132-5.

32. von Noorden GK. Infantile esotropia: a continuing riddle. Am Orthop J 1984;34:52-62.

33. Parks MM. Congenital esotropia with a bifixation result: report of a case. Doc Ophthalmol 1984; 58:109-14.

34. von Noorden GK. A reassessment of infantile esotropia. XLIV Edward Jackson memorial lecture. Am J Ophthalmol 1988;105:1-10.

35. Birch EE, Stager DR, Berry P, Everett ME. Prospective assessment of acuity and stereopsis in amblyopic esotropes following early surgery. Invest Ophthalmol Vis Sci 1990;31:758-65.

36. Harwerth RS, Smith EL, Siderov J. Behavioral studies of local stereopsis and disparity vergence in monkeys. Vision Res 1995;35:1755-70.

37. Harwerth RS, Smith EL, Crawford MLJ, von Noorden GK. Stereopsis and disparity vergence in monkeys with subnormal binocular vision. Vision Res (under review).

38. Harwerth RS, Smith EL. Contrast sensitivity for binocular disparity in monkeys with stereo-deficiencies. Invest Ophthalmol Vis Sci (Suppl) 1995;36:S954.

39. Lyle TK, Bridgeman GJO. Worth and Chavasse's squint: the binocular reflexes and the treatment of strabismus. London: Ballière, Tindall \& Cox, 1959.

40. von Noorden GK. Binocular vision and ocular motility: theory and management of strabismus. St Louis: CV Mosby, 1990.

41. Hurtt J, Rasicovici A, Windsor CE. Comprehensive review of orthoptics and ocular motility: theory, therapy, and surgery. St Louis: CV Mosby, 1972.

42. Ogle KN, Martens TG, Dyer JA. Oculomotor imbalance in binocular vision and fixation disparity. Philadelphia: Lea and Febiger, 1967.

43. Schor CM. Fixation disparity: a steady state error of 
disparity-induced vergence. Am J Optom Physiol Optics 1980;57:618-31.

44. Sheedy JE. Fixation disparity analysis of oculomotor imbalance. Am J Optom Physiol Optics 1980;57:632-9.

45. Wilson HR, Bergen JR. A four mechanism model for threshold spatial vision. Vision Res 1979;19:19-32.

46. Schor CM, Wood I. Disparity range for local stereopsis as a function of luminance spatial frequency. Vision Res 1983;23:1649-54.

47. Legge GE, Gu Y. Stereopsis and contrast. Vision Res 1989;29:989-1004.

48. Clarke WN, Noel LP. Stereoacuity testing in the monofixation syndrome. J Pediatr Ophthalmol Strabismus 1980;27:161-3.

49. Shauly Y, Prager TC, Mazow ML. Clinical characteristics and long-term postoperative result of infantile esotropia. Am J Ophthalmol 1994;117:183-9.

50. Wright KW, Edelman PM, McVey JH, Terry AP, Lin M. High-grade stereo acuity after early surgery for congenital esotropia. Arch Ophthalmol 1994;112: 913-9.

51. Schor C, Bridgeman B, Tyler CW. The spatial organization of stereopsis in strabismus. In: Spillmann L, Wooten BR, editors. Sensory experience, adapta- tion, and perception. Hillsdale, NJ: Erlbaum, 1984:623-32.

52. Schor CM, Wood I, Ogawa J. Spatial tuning of static and dynamic local stereopsis. Vision Res 1984;24: 573-87.

53. Kontesevich LL, Tyler CW. Analysis of stereothresholds for stimuli below $2.5 \mathrm{c} / \mathrm{deg}$. Vision Res 1994;34:2317-29.

54. Julesz B. Foundations of cyclopean perception. Chicago: University of Chicago Press, 1971.

55. Frisby JP, Mayhew JEW. Contrast sensitivity function for stereopsis. Perception 1978;7:423-9.

56. Simmons DR, Kingdom FAA. Contrast thresholds for stereoscopic depth identification with isoluminant and isochromatic stimuli. Vision Res 1994;34:2971-82.

57. Smallman HS, MacLeod DIA. Size-disparity correlation in stereopsis at contrast threshold. J Opt Soc Am A 1994;11:2169-83.

58. Ni J, Smith EL, Chino YM, Kitagawa K, Crawford MLJ. Cortical binocular interactions in normal and strabismic monkeys. Soc Neurosci Abstr 1990;16:984.

59. Richards W. Stereopsis and stereoblindness. Exp Brain Res 1970;10:380-8. 